Original article

\title{
Nurses' knowledge of evidence- based guidelines for preventing ventilator- associated pneumonia in intensive care units
}

\author{
Masoumeh Bagheri-Nesami i,", Maryam Amiri ${ }^{2}$
}

(Received: 19 Jun 2013; Accepted: 7 Sep 2013)

\begin{abstract}
Background and Purpose: Implementing the guidelines to prevent VAP has been shown to have a significant effect on reducing the incidence of VAP. Studies indicate that ICU staff have poor knowledge and low implementation rate of the standard preventive measures related to VAP. The present study aims to evaluate the knowledge of nurses in the intensive care unit in University hospitals of Sari.

Methods: Nurses' knowledge was assessed using a questionnaire completed by 52 ICU nurses chosen through availability sampling. The questionnaire was adopted from similar studies and included 9 questions. Validity of the questionnaire was already verified by the experts. Test-retest reliability of the questionnaire was 0.92 . Data was analyzed using descriptive statistics by SPSS software version 16.

Results: Regarding the assessment of nurses' knowledge, $34.6 \%$ of them answered correctly about oral route for endotracheal intubation; 78.8\% answered correctly about the type of humidifier; and $80.8 \%$ chose the closed suction system as the correct answer. Using kinetic beds, endotracheal tubes with extra lumens for the drainage of subglottic secretions and semi-recumbent positioning were the correct options chosen by $90.4 \%, 65.4 \%$ and $82.2 \%$ of the participants. Respondents had the least knowledge about the frequency of ventilator circuit changes $(17.3 \%)$, the frequency of humidifier changes $(3.8 \%)$ and the frequency of changes in the suction system $(13.5 \%)$.

Conclusion: The average level of the nurses' knowledge about non-pharmacological preventive measures was $51.92 \%$ which was lower compared with the surveys in the other countries, highlighting the need for more educational programs in this field. It is important to ensure that nurses receive continuous training and are involved in updating guidelines for care and behavior.

Key words: Evidence- based guidelines, Ventilator-Associated Pneumonia, ICU staff, Knowledge.
\end{abstract}

\section{Introduction}

Mechanical ventilation is associated with some complications mainly including ventilationassociated pneumonia (VAP), barotrauma, pneumothorax, pneumomediastinum, decreased cardiac output, nonoccurrence between the device and the patient's breathing and pulmonary emboli (1). VAP is defined as the pneumonia developed 48 to 72 hours after intubation $(2,3)$.

VAP is the second most common nosocomial infection $(4,5)$ and the first most prevalent infection in ICUs with the highest mortality rate among nosocomial infections (6-8). This infectious complication leads to longer hospital stays, higher costs and mortality rates (9-11). In United States, each episode of VAP is associated with 4.3 to 13 days increase in hospital stay and 12000-4000 dollars rise in therapeutic costs for each patient (12). There are various guidelines regarding preventive measures for VAP in different parts of the world (4) such as guidelines represented by Centers for Disease

\footnotetext{
${ }^{1, *}$ Corresponding author: Department of Medical Surgical Nursing, Nasibeh Nursing \& Midwifery School, Mazandaran University of Medical Sciences, Sari, Iran. Email: mbagheri@mazums.ac.ir

${ }^{2}$ Department of Medical Surgical Nursing, Nasibeh Nursing \& Midwifery School, Mazandaran University of Medical Sciences, Sari, Iran.
} 
Control (CDC), Institute of Health Care Improvement (IHI), European care bundle and clinical practice guide including semi-recumbent position, discontinuation of the sedative drugs once a day to check the possibility of extubation, using new endotracheal tubes, the drainage of subglottic secretions, using orogastric tube (OGT) and comprehensive dental and oral hygiene $(13,14)$ the administration of prophylactic agents for gastric ulcer and deep vein thrombosis (DVT) $(15,17)$, hand hygiene, staff education, using the protocol for weaning the patients from mechanical ventilation (15), oral intubation, kinetic beds, closed suction system, changing the humidifiers weekly or for each patient, changing the suction system for every new patient (16) and using gloves (17). The aim of such measures is to modify the care procedure for the patients with mechanical ventilation, leading to reduced incidence of VAP due to the implementation of the guidelines (15).

Currently there is not enough data assessing the performance of ICU staff in ICUs in Iran, particularly concerning preventive measures for VAP. Although knowledge of the guidelines does not guarantee the implementation and adherence; lack of knowledge may be a barrier to adhere to and implement VAP prevention guidelines(18). Among the ICU staff, nurses have the most critical role in implementing most of the VAP preventive measures, thus their knowledge about the subject is of great importance(19). Findings from several studies show rather low levels of nurses' knowledge about VAP preventive measures $(20,21)$. In addition, there is little data on the level of guidelines application and the compliance of the nurses with them (19). There is no doubt that in order to improve the cares and implementing the standards, the first step is to assess the current situation to pursue evidence-based strategies for improving the practice. Concludingly, this study was designed to assess nurses' knowledge in ICUs of educational hospital of Sari, Iran.

\section{Materials and Methods}

This study is a descriptive research. this study population included the nurses working in three ICUs of a university hospital in Sari, Iran. Study subjects included a total of 54 ICU nursing staff. Data was gathered using a questionnaire to evaluate the nurses' demographic data and their theoretical knowledge. The questionnaire was completed by a researcher during two months in 2012.

The nurses' demographic data (including gender, years of experience in ICU and the acquired licenses) were recorded. Their knowledge was assessed using a multiple-choice questionnaire consisting of 9 items designed by Labeau et al. (22) and then it was used and validated by Blot et al (21). Each question contains one correct answer, 2 wrong answers and one option as "I don't know". They were asked to complete the questionnaire in 15 minutes similar to the previous studies. Validity and reliability of this questionnaire have been checked somewhere else (18). The content validity of the Persian translation of the questionnaire used in our study was approved by 5 expert professionals in Mazandaran University of Medical Sciences (MAZUMS). The test-retest reliability of the questionnaire was determined as 0.92. Data was analyzed using SPSS 16. Descriptive statistics were reported as mean \pm standard deviation and percentages.

\section{Results}

Of the 52 nurses participating in the study, $84.6 \%$ were women and $15.4 \%$ were men with mean age of $32.24 \pm 7.1$. $6.5 \%$ of nurses had less than one year of ICU experience, $45.3 \% 1-5$ years, $25.8 \% 6-10$ years, and $22.4 \%$ more than 10 years' experience. $71 \%$ of respondents had a degree in emergency and critical care. Frequency of the correct answers for nine items asked in the questionnaire was as follows: oral intubation, $34.6 \%$; type of airway humidifier $78.8 \%$; closed suction system $80.8 \%$; using kinetic beds $90.4 \%$; endotracheal tubes with extra lumen for the drainage of subglottic secretions $65.4 \%$; semi-recumbent position $82.7 \%$; the frequency of humidifier changes $3.8 \%$; the frequency of change in suction system $13.5 \%$ and the frequency of ventilator circuit changes $17.3 \%$. The last 
three mentioned items had the least percentages of the correct answers among the respondents. According to this questionnaire nurses' knowledge mean level on VAP preventive measures was determined $51.92 \%$.

Table 1. Frequency of each option chosen by the nurses in the 9-item questionnaire to assess their theoretical knowledge on VAP preventive measures

\begin{tabular}{|c|c|}
\hline Multiple choice questions & $\begin{array}{c}\begin{array}{c}\text { Nurses'scores } \\
(\%)\end{array} \\
\end{array}$ \\
\hline \multicolumn{2}{|l|}{ Oral vs. nasal route for endotracheal intubation } \\
\hline a. Oral intubation is recommended & $34.6^{*}$ \\
\hline b. Nasal intubation is recommended & 42.3 \\
\hline c. Both routes of intubation can be recommended & 15.4 \\
\hline d. I don't know & 7.7 \\
\hline \multicolumn{2}{|l|}{ Frequency of ventilator circuit changes } \\
\hline a. Recommended to change circuits every $48 \mathrm{~h}$ & 42.3 \\
\hline b.Recommended to change circuits every week & 40.4 \\
\hline c.Recommended to change circuits for every new patients & $17.3^{*}$ \\
\hline d.I don’t know & - \\
\hline \multicolumn{2}{|l|}{ Type of airway humidifier } \\
\hline a. Heated humidifiers are recommended & 5.8 \\
\hline b. Heat and moisture exchangers are recommended & $78.8^{*}$ \\
\hline c. Both types of humidifiers can be recommended & 1.9 \\
\hline d. I don't know & 13.5 \\
\hline \multicolumn{2}{|l|}{ Frequency of humidifier changes } \\
\hline a. Recommended to change humidifiers every $48 \mathrm{~h}$ & 63.5 \\
\hline b. Recommended to change humidifiers every $72 \mathrm{~h}$ & 26.9 \\
\hline c. Recommended to change humidifiers every week & $3.8^{*}$ \\
\hline d. I don’t know & 5.8 \\
\hline \multicolumn{2}{|l|}{ Open vs. closed suction systems } \\
\hline a. Open suction systems are recommended & 9.6 \\
\hline b. Closed suction systems are recommended & $80.8^{*}$ \\
\hline c. Both systems can be recommended & - \\
\hline d. I don't know & 9.6 \\
\hline \multicolumn{2}{|l|}{ Frequency of change in suction systems } \\
\hline a. Daily changes are recommended & 67.3 \\
\hline b. Weekly changes are recommended & 19.2 \\
\hline c. Recommended to change systems for every new patient & $13.5^{*}$ \\
\hline d. I don’t know & - \\
\hline \multicolumn{2}{|l|}{$\begin{array}{l}\text { Endotracheal tubes with extra lumens for drainage of sub- } \\
\text { glottic secretions }\end{array}$} \\
\hline a. These endotracheal tubes reduce the risk for VAP & $65.4^{*}$ \\
\hline b. Theses endotracheal tubes increase the risk for VAP & 9.6 \\
\hline c. These endotracheal tubes do not influence the risk for VAP & 25 \\
\hline d. I don't know & - \\
\hline \multicolumn{2}{|l|}{ Kinetic vs. standard beds } \\
\hline a. Kinetic beds increase the risk for VAP & 3.8 \\
\hline b. Kinetic beds reduce the risk for VAP & $90.4^{*}$ \\
\hline c. The use of kinetic beds does not influence the risk for VAP & - \\
\hline d. I don’t know & 5.8 \\
\hline \multicolumn{2}{|l|}{ Patients positioning } \\
\hline a. Supine positioning is recommended & 5.8 \\
\hline b. Semi-recumbent positioning is recommended & $82.7^{*}$ \\
\hline c. The position of the patient does not influence the risk for VAP & 7.7 \\
\hline d. I don't know & 3.8 \\
\hline
\end{tabular}

\section{Discussion}

In this study, Iranian nurses' knowledge of VAP guidelines was evaluated. Generally, the results were average. The mean scores of the 9 items assessed in our study was $51.92 \%$ which is in consistence with the results from Blot et al (41.2\%)(21). In the study by El-khatib et al the total mean scores of the physicians, nurses and respiratory therapists was reported $80.2 \%$, $78.1 \%$ and $80.5 \%$, respectively through evaluating the level of knowledge as appropriate for all the staff (18). In comparison, the knowledge of our nurses seems inadequate and they need further education according to the new guidelines.

Evaluation of the nurses' knowledge using questionnaire showed that $34.6 \%$ of them chose the correct answer about oral route for intubation, 78.8\% were correct about the type of the humidifier and $80.8 \%$ chose closed suction system correctly. These values in Blot's study were reported $18.7 \%, 54.7 \%$ and $16.9 \%$, respectively (21). The study was done in Belgium and demonstrated the nurses' knowledge of VAP guidelines in three categories was worse than the present study. Similar to our results in the studies by Heyland et al (23) and Ricart et al (19) respectively, $80,84 \%$ of the respondents used heat and moisture exchangers. But in the study by Sierra et al (24) $96 \%$ of them used that was better than our result. Closed suction system use in Iran hospitals is very low since the system is expensive. Though, the nurses' knowledge seems to be good about this area. In Canada, closed suction systems are used in $88 \%$ of the ICUs, whereas in Spain, open tracheal suctioning was reported in $96 \%$ of the ICUs $(23,24)$.

In this study, using kinetic beds, endotracheal tubes with extra lumens for the drainage of subglottic secretions and semi-recumbent position were correctly responded by $90.4 \%, 65.4 \%$ and $82.7 \%$ of the respondents. Also, the studies semi-recumbent positioning was well acknowledged to prevent VAP (19, 23-25). Like our study, in Blot's study, $60 \%$ of the respondents knew that draining subglottic secretions decreases the risk for pneumonia. The beneficial effect 
of kinetic beds was recognized by almost half of the nurses (48.7\%). For these two issues, 28 and 31\% of the nurses, respectively, reported not to know the answers which suggest that these strategies are seldom used in ICUs. However, in our study for these two issues 5.8 and $0 \%$ of nurses, respectively, reported not to know the answer.

The items with the lowest scores were the frequency of changing ventilator circuits $(17.3 \%)$, humidifiers (3.8\%) and suction system (13.5\%). It is recommended to change airway humidification systems weekly or when clinically indicated (26). The frequency of correct answers for each item in Blot's study is better than our study and as follows: the frequency of changing ventilator circuits as $48.6 \%$; the frequency of changing humidifiers $13.3 \%$; and the frequency of changing the suction system as $19.6 \%(21)$. In the studies by Rello et al (25) and Ricart et al (19) the heat and moisture exchangers were changed on a daily basis in 59 and $75 \%$, respectively. Sierra et al found that in $75 \%$ of the ICUs, ventilator circuits were changed every $72 \mathrm{hr}$ or later (24). This is in line with Blot's findings where nurses indicated to change circuits weekly or later in $76 \%$ of the respondents. The results of El-khatib et al's study indicated that the participants were most frequently correct about using an endotracheal tube with a lumen than usual for the drainage of subglottic secretions and about using open versus closed suction systems. Respondents had the least knowledge about the frequency of humidifier changes and the optimal frequency of ventilator circuit changes (18).

Our study findings demonstrate that nurses' knowledges about VAP guidelines is not good, and highlights the need for comprehensive education based on the current recommendations. One might question the importance of pure knowledge versus the application degree in practice. We believe that thorough understanding of the recommended strategies supports the adherence and overcomes potential barriers as previously identified $(19,21,25)$. Additionally, increasing the average level of knowledge has been the first step in successful multifaceted educational programs(27). The results of another study underline the importance of having a continuous training programme for nursing and ICU staff, indicating the need to ensure that all ICU staff work together on the preparation and regular updating of evidence-based clinical and nursing protocols and guidelines (28).

\section{Conclusion}

The results of the surveys with this questionnaire can be used to focus educational programs on VAP. The questionnaire can also be used before and after educational programs to assess the effect of the programs on nurses' knowledge of interventions to prevent VAP. Guidelines to prevent VAP can change over time. Adaptation and reevaluation of the questionnaire will be needed each time new evidencebased interventions for preventing VAP are discovered.

\section{Conflict of interests}

The authors declare that they have no competing interests.

\section{Author's contributions}

M.Bagheri-Nesami and M.Amiri have contributed to the designing, writing, revising and approving the final manuscript. M.Amiri have performed data collection and M.Bagheri-Nesami have done statistic analysis.

\section{Acknowledgment}

We appreciate the assistant directors and staff of three educational hospital ICUs staff of Sari.

\section{References}

1. Villar J, Blanco J, Zhang H, Slutsky AS. Ventilatorinduced lung injury and sepsis: two sides of the same coin? Minerva Anestesiol 2011; 77(6): 647-653.

2. Fink M.P, Abraham E, and Vincent J. Text book of Critical Care: London: Saunders, 2005.

3. Toress A, Ferrer M, Badia JR. Treatment, Guidelines and outcomes of hospital-acquired and ventilator associated pneumonia. Clin Infect Dis 2010; 51(9): 48-53. 
4. Hsieh HY, Tuite PK. prevention of ventilator-associated pneumonia, what nurses can do. Dimense critical care nurse 2006; 25(5): 205-208.

5. Augustyn B. Ventilator-associated pneumonia: Risk factors and prevention. Crit Care Nurse 2007; 27(4): 32-6, 38-39.

6. Albertos R, Caralt B, Rello J. Ventilator-associated pneumonia management in critical illness. Curr Opin Gastroenterol 2011; 27(2): 160-166.

7. Ruffell A, Adamcov L. Ventilator-associated pneumonia: prevention is better than cure. Nurs Crit Care 2008; 13(1): 44-53.

8. Melsen W, RoversM, Bonten M. Ventilator-associated pneumonia and mortality: A systematic review of observational studies. Crit Care Med 2009; 37(10): 2709-2718.

9. Safdar N, Dezfulian C. Clinical and economical consequences of ventilator-associated pneumonia: A systematic review. Crit Care Med 2005; 33(10): 2184-2193.

10. Lisboa T, Rello J. Diagnosis of ventilator-associated pneumonia: Is there a gold standard and a simple approach? Curr Opin Infect Dis 2008; 21(2): 174-178.

11. Marra AR, Cal RG, Silva CV, Caserta RA, Paes AT, Moura DF, et al. Successful prevention of ventilatorassociated pneumonia in an intensive care setting. Am J Infect Contro? 2009; 37(8): 619-625.

12. Powers J, Brower A, Tolliver S. Impact of oral hygiene on prevention of ventilator-associated pneumonia in neuroscience patients. J Nurs Care Qual 2007; 22(4): 316-320.

13. Darves B. Seven strategies to prevent VAP: a look at the evidence. Todays hospitalist. 2005 May.

14. Cason C. L, Tyner T, Saunders S, Broome L. Nurses implementation of guidelines for VAP from the centers for control and prevention. Am J Crit Care. 2007; 16(1): 28-37.

15. Rello J, Lode H, Cornaglia G, Masterton R. A European care bundle for prevention of ventilator-associated pneumonia. Intensive Care Med 2010; 36(1): 773-780.

16. Muscedere J, Dodek P, Keenan S, Fowler R, Cook D, Heyland D. Comprehensive evidence-based clinical practice guidelines for ventilator-associated pneumonia: prevention. J Crit Care 2008; 23(1): 126-137.

17. Abbott CA, Dremsa T, Stewart DW, Mark DD, Swift CC. Adoption of a ventilator-associated pneumonia clinical practice guideline. Worldviews Evid Based
Nurs 2006; 3(4): 139-152.

18. El-Khatib MF, Zeineldine S, Ayoub C, Husari A, BouKhalil PK. Critical care clinicians' knowledge of evidencebased guidelines for preventing ventilator associated pneumonia. Am J Crit Care 2010; 19(3): 272-276.

19. Ricart M, Lorente C, Diaz E, Kollef MH and Rello J. Nursing adherence with evidence-based guidelines for preventing ventilator-associated pneumonia. Crit Care Med 2003; 31(11): 2693-2696.

20. Meherali SM and Y Parpio. Nurses' knowledge of evidence-based guidelines for prevention of ventilator associated pneumonia in critical care areas: a pre and post test design. J Ayub Med Coll Abbottabad 2011; 23(1): 146-149.

21. Blot SI, Labeau S, Vandijck D, Van Aken P. Evidence based guidelines for the prevention of ventilator associated pneumonia: results of a knowledge test among intensive care nurses. Intensive Care Med 2007; 33(8): 1463-1467.

22. Labeau S, Vandijck D, Claes B, Vanaken P, Blot S. Critical care nurses' knowledge of evidence based guidelines for preventing ventilator-associated pneumonia: an evaluation questionnaire. Am J Crit Care 2007; 16(4): 371-377.

23. Heyland DK, Cook DJ, Dodek PM. Prevention of ventilator associated pneumonia: current practice in Canadian critical care units. J Crit Care 2002; 17(3): 161-167.

24. Sierra R, Benitez E, Leon C, Rello J. Prevention and diagnosis of ventilator-associated pneumonia: survey on current practices in Southern Spanish CCUs. Chest 2005; 128(3): 1667-1673.

25. Rello J, Lorente C, Bodi M, Diaz E, Ricart M and et al. Why physicians follow do not evidencebased guidelines for preventing ventilator associated pneumonia: a survey based on the opinions of an international panel of intense visits. Chest 2002; 122(2): 656-661.

26. Dodek P, Keenan S, Cook D, Heyland D, Jacka M, Hand L, et al. Evidence-based clinical practice guideline for the prevention of ventilator-associated pneumonia. Ann Intern Med 2004; 141(4): 305-313.

27. Berenholtz SM, PronovostPJ, Lipsett PA, Hobson $\mathrm{D}$, Earsing $\mathrm{K}$ and et al. Eliminating catheter-related bloodstream infections in the critical care unit. Crit Care Med 2004; 32(10): 2014-2020. 